University of Wollongong

Research Online

Faculty of Engineering and Information

Faculty of Engineering and Information

Sciences - Papers: Part A

Sciences

$1-1-2015$

\title{
A laboratory study on the shear behavior of mixtures of coal wash and steel furnace slag as potential structural fill
}

Seyed M.A Tasalloti

University of Wollongong, smat777@uowmail.edu.au

Buddhima Indraratna

University of Wollongong, indra@uow.edu.au

Cholachat Rujikiatkamjorn

University of Wollongong, cholacha@uow.edu.au

Ana Heitor

University of Wollongong, aheitor@uow.edu.au

Gabriele Chiaro

University of Wollongong, gchiaro@uow.edu.au

Follow this and additional works at: https://ro.uow.edu.au/eispapers

Part of the Engineering Commons, and the Science and Technology Studies Commons

Research Online is the open access institutional repository for the University of Wollongong. For further information contact the UOW Library: research-pubs@uow.edu.au 


\title{
A laboratory study on the shear behavior of mixtures of coal wash and steel furnace slag as potential structural fill
}

\author{
Abstract \\ The accumulation of industrial waste materials (e.g., coal wash and steel furnace slag) has become a \\ critical environmental problem in Australia in recent years. The possible re-use of these types of materials \\ as structural fill for transport embankments and land reclamation is one of the preferred options from a \\ waste management perspective. Consequently, an experimental testing program was undertaken using \\ the triaxial apparatus to evaluate the shear behavior of compacted mixtures of coal wash (CW) and steel \\ furnace slag (SFS). The effect of varying the confining pressure and the percentage of coal wash on the \\ isotropic compression line, the stress-strain behavior, and particle degradation during drained shearing \\ was evaluated. The percentage of coal wash was found to influence the shearing behavior of the CW-SFS \\ mixtures. When the content of coal wash increased, the shear strength of the CW-SFS mixtures decreased \\ and the axial strain corresponding to the peak stress ratio increased. Moreover, the incidence of particle \\ breakage increased for those mixtures with a higher $\mathrm{CW}$ content due to the low particle strength of $\mathrm{CW}$. \\ This paper also provided a non-linear strength envelope and a corresponding empirical equation to \\ capture the shear strength of CW-SFS mixtures.

\section{Disciplines} \\ Engineering | Science and Technology Studies

\section{Publication Details} \\ Tasalloti, S. M. A., Indraratna, B., Rujikiatkamjorn, C., Heitor, A. \& Chiaro, G. (2015). A laboratory study on \\ the shear behavior of mixtures of coal wash and steel furnace slag as potential structural fill. \\ Geotechnical Testing Journal, 38 (4), 361-372.
}




\title{
A laboratory Study on the Shear Behaviour of Mixtures of Coal Wash and Steel Furnace Slag as Potential Structural Fill
}

\author{
Seyed M. A. Tasalloti \\ BSc (Hons, Iran), MSc (Iran) \\ $\mathrm{PhD}$ candidate, Centre for Geomechanics and Railway Engineering, \\ University of Wollongong, Wollongong, NSW 2522, Australia
}

\author{
Buddhima Indraratna $\uparrow$ \\ BSc (Hons, London), MSc (London), PhD (Alberta), DIC, FIEAust., FASCE, \\ FTSE, FGS \\ Professor of Civil Engineering, Director, Centre for Geomechanics and \\ Railway Engineering, University of Wollongong, Wollongong, NSW 2522, Australia
}

\section{Cholachat Rujikiatkamjorn}

BEng (Hons), MEng (AIT), PhD (Wollongong)

Associate Professor of Civil Engineering, Centre for Geomechanics and Railway Engineering, University of Wollongong, Wollongong, NSW 2522, Australia

\author{
Ana Heitor \\ LicEng (Lisbon), MEng (Kyoto) \\ Lecturer, Civil Engineering, Centre for Geomechanics and Railway \\ Engineering, University of Wollongong, Wollongong, NSW 2522, Australia \\ Gabriele Chiaro \\ BSc (Italy), MSc (Italy), PhD (Tokyo) \\ Formerly Research Fellow, Centre for Geomechanics and Railway \\ Engineering, University of Wollongong, Wollongong, NSW 2522, Australia
}

$\dagger$ Author for correspondence:

Prof. Buddhima Indraratna

School of Civil Engineering,

Faculty of Engineering, University of Wollongong

Wollongong, NSW 2522

AUSTRALIA

Ph: +61 242213046

Fax: +61 242213238

Email: indra@uow.edu.au

To be submitted to: Geotechnical Testing Journal 


\title{
A laboratory Study on the Shear Behaviour of Mixtures of Coal Wash and Steel Furnace Slag as Potential Structural Fill
}

Seyed M. A. Tasalloti, Buddhima Indraratna, Cholachat Rujikiatkamjorn, Ana Heitor, and

Gabriele Chiaro

\begin{abstract}
The accumulation of industrial waste materials (e.g. coal wash and steel furnace slag) has become a critical environmental problem in Australia in recent years. The possible re-use of these types of materials as structural fill for transport embankments and land reclamation is one of the preferred options from a waste management perspective. Consequently, an experimental testing program was undertaken using the triaxial apparatus to evaluate the shear behaviour of compacted mixtures of coal wash (CW) and steel furnace slag (SFS). The effect of varying the confining pressure and the percentage of coal wash on the isotropic compression line, the stress-strain behaviour, and particle degradation during drained shearing was evaluated. The percentage of coal wash was found to influence the shearing behaviour of the CW-SFS mixtures. When the content of coal wash increased the shear strength of the CW-SFS mixtures decreased and the axial strain corresponding to the peak stress ratio increased. Moreover, the incidence of particle breakage increased for those mixtures with a higher $\mathrm{CW}$ content due to the low particle strength of $\mathrm{CW}$. This paper also provides a non-linear strength envelope and a corresponding empirical equation to capture the shear strength of CW-SFS mixtures.
\end{abstract}

Keywords: coal wash, steel furnace slag, stress-strain behaviour, particle breakage, triaxial compression 


\section{Introduction}

Due to the worldwide increase in urbanisation and population density, the need for more land to accommodate new infrastructure, including the expansion of the existing ports, has increased substantially in recent years. In many countries where there is no shortage of conventional fill materials (e.g. sand and gravel) and the cost of using quarries is relatively low, these materials are largely used for embankments and land reclamation projects (Massarsch, 1991, Watts and Cooper, 2011, Zekkos and Flanagan, 2011). However, the use of fresh aggregates is often uneconomical and also the production of industrial waste materials such as coal wash and steel furnace slag from mining activities and steel making has been rapidly increasing (Leventhal, 1996, Geiseler, 1996). Therefore, from a waste management perspective, recycling and re-using industrial by-products rather than disposal, is an alternative and much preferred method.

There are many examples where industrial by-products such as steel slag and coal washery rejects have been used in civil engineering projects such as road embankments, reclamation fill, asphalt aggregates, concrete aggregate, and subgrade fill (Indraratna et al., 1994, Rai et al., 2002, Dippenaar, 2005, Lim and Chu, 2006, Okabue and Ochulor, 2007, Safiuddin et al., 2010, Malasavage et al., 2012, Indraratna et al., 2013a). Most of these applications and subsequent studies only focused on one type of waste material, not as a mixture. It is already known that using steel slag on its own can pose a serious problem with infrastructure because of its potential towards swelling (Wang, 2010; Wang et al., 2010), and although not expansive, coal washery rejects can cause differential settlement due to particle degradation or collapse (Pusadkar and Ramasamy, 2005). On the basis that the 
adverse effects of both materials might be diminished by mixing them together, an in-depth study of the behaviour of blended waste materials on coal wash and steel furnace slag is therefore essential.

This study is part of an industrial project for the Port Kembla Outer Harbour extension in Wollongong, NSW Australia. The project involves reclaiming approximately 42 hectares of land to accommodate new berthing and factory facilities (Lai et al., 2011). Due to the abundance of industrial waste material in this region, by-products such as coal wash and steel furnace slag were considered to be potential structural fill material for the above tide level.

In this study the behaviour of mixtures of coal wash and steel furnace slag where the content of coal wash ranged from $0 \%$ (i.e., pure steel furnace slag) to $100 \%$ (i.e., pure coal wash) has been studied. Different mixtures of 0/100, 75/25, 50/50, 25/75, 100/0 (percentage of CW/SFS based on their over-dried weight) were tested under drained triaxial condition to evaluate their long term shear behaviour. The preliminary studies indicated that the permeability of these mixtures were high enough such that under port loading conditions a drained state could be maintained (Chiaro et al., 2014b). In addition, the effects of the confining pressure and percentage of coal wash on the mechanical behaviour of CW-SFS mixtures such as the stress-strain and volumetric strain behaviour, strength envelopes, critical state lines, isotropic compression lines, and particle breakage were evaluated. The results of this study indicated that blended waste materials consisting of CW and SFS can potentially be used as structural fill. 


\section{Materials and Experimental Program}

\section{Material Tested}

The CW produced in a local colliery near the city of Wollongong is a very dark and heterogeneous material, while the SFS is produced via the basic oxygen method by the Australian Steel Mill Services. These CW and SFS materials are granular and have specific gravities $\left(G_{s}\right)$ of 2.27 and 3.34, respectively. (Rujikiatkamjorn et al., 2013). The relatively low value of the specific gravity for CW is attributed to its mineralogical composition which mainly consists of coal residuals, ash, and carbon, which have lower specific gravity than natural soils, whereas in SFS the presence of metal compounds (e.g. $\left.\mathrm{Fe}_{2} \mathrm{O}_{3}, \mathrm{SiO}_{2}\right)$ and free lime $(\mathrm{CaO})$ resulted in a relatively high specific gravity. In brief, both CW and SFS are considerably different to natural soils which contain predominantly quartz or clay minerals. The original particle size distributions (PSD) of individual CW and SFS and the PSD adopted for triaxial testing are plotted in Fig. 1. Due to adhesion between the coarse and fine particles, the wet sieving method was used (ASTM D1140-14). In terms of particle size distribution alone, CW and SFS can be classified as equivalent to materials conforming to GW-GM and SW, respectively, according to the Unified Soil Classification System (USCS).

Due to particle degradation during compaction, the PSD used for triaxial testing was based on the PSD obtained after the material was compacted in a field trial at Port Kembla, the commercial port of Wollongong. It was observed that most of the larger particles $(>16 \mathrm{~mm})$ of $\mathrm{CW}$ were easily broken down into smaller sizes during compaction. Much of the particle breakage appeared to be split across the main body of the particle rather than just abrading the angular edges and corners, and this was 
mainly the result of the compaction process. Since the shear behaviour of granular material is influenced by the initial PSD, all the mixtures were prepared with the same initial PSD (Fig. 1) to exclude the effect of initial gradation on its behaviour, as has been observed in other studies (Indraratna et al., 1998, Ni et al., 2000, Cerato and Lutenegger, 2006).

\section{Experimental Program and Specimen Preparation}

In order to establish the geotechnical characteristics of the mixtures between Coal Wash (CW) and Steel Furnace Slag (SFS), and to evaluate the effect of variations in the $\mathrm{CW}$ and the effective confining pressure, five isotropic compression tests and 20 consolidated drained triaxial tests were conducted on five different mixtures. The mixtures are expressed as $\mathrm{CW}-\mathrm{SFS}$, where $\mathrm{CW}=$ coal wash and $\mathrm{SFS}=$ steel furnace slag, and the numbers after CW and SFS are the percentages of coal wash and steel furnace slag corresponding to the oven-dried weight in the mixtures, respectively. Table 1 presents the conditions of these tests and shear strength parameters (peak friction angle, peak deviator stress, and peak mean stress). An effective confining pressure in the range of $30-220 \mathrm{kPa}$ was applied to mimic the port loading conditions (Lai et al., 2011). Lower limit of confining pressure (i.e. $30 \mathrm{kPa}$ ) was considered for the shallow areas in the port where only a small surcharge load is applied on the pavements, while the upper limit of confining pressure (i.e. $220 \mathrm{kPa}$ ) would be larger than the maximum live load that is expected during the design life owing to heavy infrastructure including container warehouses. To avoid any boundary effects related to the largest particle size as suggested in ASTM D7181 (2011), the drained triaxial tests were performed on specimens that were $100 \mathrm{~mm}$ in diameter and $200 \mathrm{~mm}$ in height. 
Blended waste materials were prepared by mixing different percentages of ovendried SFS and CW, by weight. According to the particle sizes typically available for these waste materials, CW and SFS were initially sieved into eight particle sizes (i.e., $13.2,9.5,6.7,4.75,2.36,1.18,0.6$, and $<0.6 \mathrm{~mm})$. In order to obtain the PSD curve shown in Fig. 1, the exact amounts of each size were weighed and mixed thoroughly until the CW-SFS mixture attained a uniform appearance. Water was then added to the mixtures until $7 \%$ moisture was obtained. This moisture content was based on field measurement during compaction. Triaxial specimens were prepared and compacted directly on the bottom triaxial pedestal with a split mould using a hammer (500g weight subjected to a drop height of $320 \mathrm{~mm}$ ). For all tests the specimens were prepared at an initial dry density equal to their 90\% MDD (Maximum Dry Density). Each specimen was compacted in seven layers $(28.6 \mathrm{~mm} / \mathrm{layer})$ and with 30 drops of the hammer per layer (total applied energy is equal to $205 \mathrm{~kJ} / \mathrm{m}^{3}$ ). To avoid friction between the mould and the specimen, a membrane was placed inside the mould, and after compaction, a new membrane was replaced during the shearing stage.

After compaction the cell was then assembled and filled with water, and a pressure of $10 \mathrm{kPa}$ was applied to make sure the specimen would not deform. To saturate the specimens, they were initially flooded with water from the base while the air was expelled via the top cap. The rate of water injected into the specimen was slow enough to prevent any fine particle migration inside the specimen. After this a saturation stage was applied while maintaining an effective stress of $10 \mathrm{kPa}$ until the back pressure reached $400 \mathrm{kPa}$. The specimens were held under this pressure until the Skepmton's B parameter reached a value higher than 0.97 . The specimens were then consolidated isotropically to the desired four levels of mean effective stress reported 
in Table 1, and then sheared at a constant rate of displacement of $0.2 \mathrm{~mm} / \mathrm{min}(6 \% / \mathrm{h})$, in accordance with ASTM D7181 (2011). During consolidation and shearing, the drainage valve remained open to maintain a drained condition.

Two methods were used to correct the cross sectional area during shearing, depending on the volumetric shear behaviour of the specimen. The cross sectional area of those specimens indicating contraction was corrected according to ASTM D7181 (2011), and the above correction for pre-peak range was also used for those specimens showing dilation, and the method proposed by La Rochelle et al., (1988) was used after the post-peak range.

\section{Results and Discussion}

\section{Isotropic Compression Behaviour}

The effect that the percentage of $\mathrm{CW}$ has on the isotropic compression characteristics of CW-SFS mixtures was investigated first, and the results of this study associated with five different mixtures are shown in Fig. 2. Although all the mixtures were prepared to the same degree of compaction (90\% MDD for each mixture), the initial specific volume $\left(v_{0}\right)$ varied in different mixtures due to the variation of $G_{s}$ (see Table 1). For all cases except CW50-SFS50, the specimens were isotropically consolidated to a mean effective stress of $1.3 \mathrm{MPa}$ which is considered to cover the confining pressure under port conditions and to reach the yield or past stress induced by compaction, and to evaluate the elastic parameters of the CW-SFS mixtures an unloading-reloading stage was carried out. For the sake of clarity, the vertical axis in Fig. 2 was normalised to $v_{0}$. Each mixture experienced three distinct stages of deformation; the initial elastic region (Region 1) where the change in specific volume over the pressure was very small, and the second region where compression 
gradually increased with the applied stress (Region 2). In this region the Equivalent Past Stress $\left(p^{*}\right)$ can be determined using the Casagrande method (Casagrande, 1936), and the values of $p^{*}$ are shown in Fig. 3. Although all the mixtures were prepared under the same compaction energy, the equivalent past stress $\left(p^{*}\right)$ decreased significantly with the increase in CW content (i.e. from $850 \mathrm{kPa}$ for CW0-SFS100 to 250kPa for CW100-SFS0). This can be attributed to relatively weak particles of CW and their inevitable breakage. Region 3 is beyond the yield point where there was a significant change in the specific volume under increasing mean effective stress, and in this region the slope of isotropic compression line (ICL) can be determined. The values of $N$ (the specific volume corresponding to $p^{\prime}=1 \mathrm{kPa}$ ), $\lambda_{\text {ISO }}$ (slope of isotropic compression line), and $\kappa$ (unloading-reloading slope) are listed in Table 1. The results of ICL on the CW-SFS mixtures indicated that the amount and rate of compression increased as the percentage of $\mathrm{CW}$ increased, even though the initial void ratio of this mixture with a higher $\mathrm{CW}$ content was actually smaller. This could be attributed to the breakage of $\mathrm{CW}$ particles at the same mean effective stress.

By normalising the value of the mean effective stress to $p^{*}$ for each mixture, the results of ICL for all the mixtures follow a unique trend which are illustrated in Fig. 3. The ICL of different mixtures can be predicted using the following empirical bilinear equations:

$$
\begin{array}{ccc}
\frac{v}{v_{0}}=1-0.026 \frac{p^{\prime}}{p^{*}} & \text { for } \frac{p^{\prime}}{p^{*}}<1.5 \quad\left(R^{2}>0.96\right) \\
\frac{v}{v_{0}}=0.98-0.016 \frac{p^{\prime}}{p^{*}} & \text { for } \frac{p^{\prime}}{p^{*}}>1.5 \quad\left(R^{2}>0.96\right)
\end{array}
$$




\section{Stress-Strain Behaviour}

In this section the results of consolidated isotropic drained (CID) triaxial tests for five different mixtures of CW and SFS are presented. The specimens were consolidated to four different effective confining pressures and then sheared under drained conditions. Table 1 presents a summary of the CID triaxial test, including the peak deviatoric stress $\left(q_{\text {peak }}\right)$, the peak mean effective stress $\left(p_{\text {peak }}^{\prime}\right)$, the peak friction angle $\left(\phi_{\mathrm{p}}^{\prime}\right)$, and the critical state parameters. Typical triaxial results are presented in Figs. 4 and 5. Figure 4 shows the deviatoric stress-strain, volumetric strain, stress path, and critical state line (CSL) for the C50-S50 mixture under four effective confining pressures. By increasing the effective confining pressure from $30 \mathrm{kPa}$ to $220 \mathrm{kPa}$, the peak deviatoric stress $\left(q_{\text {peak }}\right)$, the axial strain at $q_{\text {peak }}$, the amount of volumetric contraction, and the initial deformation modulus increased correspondingly. Under low confining pressures (i.e. $30 \mathrm{kPa}$ and $60 \mathrm{kPa}$ ), the volumetric responses of the mixture initially indicated a small contraction followed by volumetric dilation, and the peak deviatoric stress occurred at maximum dilation. In contrast, at higher effective confining pressures there was only contractive behaviour, which means that the dilative and contractive behaviour of any mixture depends on the initial void ratio and confining pressure (i.e. the location of initial conditions compared to the CSL) (Roscoe et al., 1963, Rowe, 1962, Been and Jefferies, 1985). With those specimens on the dry side of CSL, there was dilative behaviour in volumetric strain and peak-softening in stress-strain, and with the specimen on the wet side of CSL, there was volumetric contraction and hardening in deviatoric stress. This behaviour was similar to that reported by a number of previous studies on the behaviour of granular material, for instance, as discussed by Indraratna et al., (1998), Modoni and Gazzellone, (2011), and Chiaro et al., 2014a. 
Figure 5 illustrates the typical stress-strain behaviour of all the mixtures under effective confining pressures of $30 \mathrm{kPa}$ and $120 \mathrm{kPa}$, and it was evident that the $\mathrm{CW}$ content had a significant influence on the shear behaviour. Once the percentage of $\mathrm{CW}$ increased the peak deviatoric stress decreased, and the specimen generally showed a higher volumetric strain. Furthermore, the initial deformation modulus also decreased in mixtures having a higher percentage of CW such that the increased amount of CW changed the stress-strain response of CW-SFS mixtures from brittle to ductile. CW0-SFS100 always showed a higher deviatoric stress than the other mixtures but at a larger axial strain this difference was marginal. Under $30 \mathrm{kPa}$ of effective confining pressure all the mixtures exhibited a peak and post-peak softening whereas under $120 \mathrm{kPa}$, only the CW0-SFS100 showed a similar trend, while there was a strain hardening response in all the remaining mixtures. The $\varepsilon_{v}-\varepsilon_{1}$ curves plotted in Fig. 5 also showed that increasing the percentages of CW also increased the volumetric contraction for a given effective confining pressure. However, the effect of $\mathrm{CW}$ on the volumetric strain diminished at higher effective confining pressure, where all the mixtures except CW0-SFS100 exhibited contractive behaviour. The significant contraction of CW100-SFS0 might be attributed to the increased breakage in CW particles compared to the SFS particles. The degradation of CW-SFS mixtures with a breakage analysis will be discussed later.

It is evident from Fig. 5 that the concept of a critical state can be applied to CW-SFS mixtures because the deviatoric stress and change in volume for all the mixtures of CW-SFS approached an almost constant value at the end of each test (for an axial strain larger than 20\%). In Fig. 6 the stress paths in $v$-lnp' space are plotted such that the solid points represent the values of $v$ and $p^{\prime}$ at the end of tests. It was evident that 
a higher percentage of $\mathrm{CW}$ increased the slope of the critical state line $\left(\lambda_{\mathrm{CSL}}\right)$, but there was little change in $\lambda_{\mathrm{CSL}}$ for those mixtures containing more than $50 \%$ coal wash. Figure 6 clearly shows the dilative behaviour of those specimens that were initially below CSL and the volumetric contraction for those above CSL.

Figure 7 illustrates the volumetric strain at the critical state against the effective confining pressure for all the CW-SFS mixtures. As expected, under low effective confining pressure volumetric dilation occurred during shearing and once the effective confining pressure increased, the mixtures showed volumetric contraction at a decreasing rate. Under a given effective confining pressure those mixtures with a higher percentage of $\mathrm{CW}$ exhibited more contraction partly due to particle breakage during shearing. In the range of $50-100 \mathrm{kPa}$ effective confining pressure, the mixtures CW75-SFS25, CW50-SFS50, and CW25-SFS75 showed no change in volume at the end of the test; in fact the only mixture that showed dilation, even at a high effective confining pressure (220kPa), was CW0-SFS100.

\section{Shear Strength Characteristics}

Since both CW and SFS are granular materials their shear behaviour was mainly influenced by the peak friction angle $\left(\phi_{\mathrm{p}}\right)$ and the effective confining pressure. Figure 8(a) presents the peak deviatoric stress and peak mean effective stress against confining pressure. As expected, the $q_{p e a k}$ and $p_{\text {peak }}^{\prime}$ increased with the effective confining pressure and the content of SFS; both $q_{\text {peak }}$ and $p_{\text {peak }}^{\prime}$ showed a non-linear relationship with the effective confining pressure and the slope of these curves decreased when the effective confining pressure increased. This implies that the 
influence of SFS on the shear behaviour was suppressed at higher effective confining pressures.

An empirical equation based on the above observations to predict the $q_{p e a k}$ and $p_{\text {peak }}^{\prime}$ for the CW-SFS mixtures compacted at $90 \%$ MDD can be expressed by:

$$
\begin{aligned}
& q_{\text {peak }}=a\left(\sigma_{3}^{\prime}\right)^{b} \\
& p_{\text {peak }}^{\prime}=m\left(\sigma_{3}^{\prime}\right)^{n}
\end{aligned}
$$

where $a, b, m$ and $n$ are empirical coefficients that depend on the percentage of CW, and they were defined by the curve fitting for the experimental results on the materials tested in this study. It is important to mention that due to some variation of the properties of CW and SFS, these coefficients might be altered depending on the source materials. These coefficients can be determined by the following expressions:

$$
\begin{array}{ll}
a=18.75 e^{-0.009 \alpha} & \left(R^{2}>0.94\right) \\
b=0.00136 \alpha+0.67 & \left(R^{2}>0.98\right) \\
m=7.04 e^{-0.008 \alpha} & \left(R^{2}>0.96\right) \\
n=0.00142 \alpha+0.77 & \left(R^{2}>0.96\right)
\end{array}
$$

where $\alpha$ is the value of $\mathrm{CW}$ expressed in percentage.

The variations of peak friction angle $\left(\phi_{\mathrm{p}}\right)$ and peak stress ratio against the effective confining pressure for CW-SFS mixtures are shown in Fig. 8(b). All the CW-SFS mixtures showed a non-linear relationship between $\phi_{\mathrm{p}}$ and $\sigma_{3}^{\prime}$. This is in agreement with past studies on granular materials, as reported by Indraratna et al., 2013b. The peak friction angle increased with the SFS content but diminished as $\sigma_{3}^{\prime}$ increased. Under low $\sigma_{3}^{\prime}$ the volumetric behaviour of the CW-SFS mixtures was dilative, so $\phi_{\mathrm{p}}$ was greater than the critical state friction angle $\left(\phi_{\mathrm{cs}}\right)$. It was expected that $\phi_{\mathrm{p}}$ would 
approach $\phi_{\mathrm{cs}}$ at a higher confining pressure where dilation was absent. Figure $8(b)$ also shows that the difference of $\phi_{\mathrm{p}}$ between the mixtures with a higher percentage of SFS and those with less SFS was large under smaller values of $\sigma_{3}^{\prime}(<120 \mathrm{kPa})$, and this difference decreased significantly once $\sigma_{3}^{\prime}$ increased. This means that the influence of SFS percentage on $\phi_{\mathrm{p}}$ was greater at low confining pressures, and this influence was less pronounced when $\sigma_{3}^{\prime}$ increased.

The shear strength envelopes of CW-SFS mixtures can be characterised quite well in terms of the peak stress ratio $(q / p)_{\text {peak }}$ to the corresponding confining pressure (Fig. $8(b))$. The following non-linear relationship can be derived using Eqs 2 and 3 for the shear strength envelopes of CW-SFS mixtures.

$$
\left(\frac{q}{p^{\prime}}\right)_{\text {peak }}=\frac{a}{m}\left(\sigma_{3}^{\prime}\right)^{b-n}
$$

The results of this study indicated that the peak stress ratio increased as the CW percentage in the mixture decreased. The observed increase in $(q / p)_{\text {peak }}$ could be attributed to the greater inter-particle friction angle and interlocking SFS particles.

Variation of secant shear modulus $\left(G_{s e c}\right)$ with shear strain for CW-SFS mixtures under four confining pressures are presented in Fig. 9. The contours of shear strains corresponding to three levels of peak stress (e.g. $0.25 q_{\text {peak }}, 0.5 q_{\text {peak }}$, and $0.75 q_{\text {peak }}$ ) are also plotted as dashed lines. It was observed that the addition of a small amount of SFS in the mixture influenced significantly the $G_{s e c}$ (e.g. secant shear modulus corresponding to $0.5 \%$ axial strain under $120 \mathrm{kPa}$ confining pressure were around $11 \mathrm{MPa}$ and $18 \mathrm{MPa}$ for CW100-SFS0 and CW75-S25, respectively). Under low confining pressure (less than $60 \mathrm{kPa}$ ), a region where secant shear modulus was 
constant could be defined (range of $0.1 \%$ to $0.4 \%$ strain). In this region the behaviour of CW-SFS mixtures was observed to be linear elastic. However, beyond this region the nonlinear behaviour of CW-SFS was clearly visible. The shear strain corresponding to $0.25 q_{\text {peak }}$ under four confining pressures was constant for all mixtures except CW100-SFS0. This implies that the deformation to mobilize $25 \%$ of peak strength is relatively independent of the confining pressures. Figure 9 also shows that the shear strain corresponding to any levels of shear stress (under any given confining pressure) increased once the $\mathrm{CW}$ percentage increased in the mixture. This specifies that more deformation is expected for mixtures with higher CW percentage under any given loading.

The axial strains vs confining pressure corresponding to peak stress and $50 \%$ peak stress are plotted in Fig. 10, and it shows that under a given effective stress, a greater axial strain was needed to mobilise $\phi_{\mathrm{p}}$ for mixtures with higher content of $\mathrm{CW}$. Under smaller effective confining pressures (e.g., $\sigma_{3}^{\prime}<60 \mathrm{kPa}$ ), the corresponding axial strain at peak stress was less than $2 \%$ for most CW-SFS mixtures (except CW100-SFS0), whereas for $\sigma_{3}^{\prime}>120 \mathrm{kPa}$ the $\varepsilon_{a}$ was greater than $10 \%$ (Fig. 10(a)). In performance based design, engineers are interested in determining the level of strain that corresponds to the mobilised shear stress. Figure $10(b)$ presents the axial strain corresponding to $50 \%$ peak stress (i.e. factor of safety $=2$ ), and shows that for most of CW-SFS mixtures, the strain required to mobilise $0.5 q_{\text {peak }}$ is less than $1 \%$. This implies that in a practical application such as typical port conditions, the expected strain under the loading levels would be smaller than $1 \%$ by limiting the applied load to within $50 \%$ of its peak strength. Based on Fig. 10(b), one may conclude that most 
mixtures apart from CW100-SFS0 can be used as structural fill in terms of strain levels.

\section{Degradation of CW-SFS Mixtures}

Particle breakage influences the strength and deformation characteristics of CW-SFS mixtures because it imposes increased volumetric contraction during shearing. To determine the degradation of CW-SFS mixtures, a wet sieve analysis was conducted on the specimens after triaxial shearing. By quantifying the change in PSD before and after shearing, the breakage index (BI) can be determined. In this investigation the particle degradation of CW-SFS mixtures was evaluated by adopting the method originally proposed by Indraratna et al., (2005) and then modifying it to suit these waste materials. This modification includes adjusting the arbitrary boundary of maximum breakage which depends on the particle size distribution of the materials. The Breakage Index (BI) can be defined as:

$$
B I=\frac{A}{A+B}
$$

where $A$ and $B$ represent the area between an arbitrary line (the maximum breakage possible) and the PSD before and after shearing respectively. In Fig. 11 the definition of " $A$ " and " $B$ " are presented.

Figure 12 presents the BI analysis for CW-SFS mixtures subjected drained triaxial tests. The Hardin's method (Hardin, 1985) for breakage quantification is also plotted for comparison. These results include particle breakage while the specimens were being prepared. The breakage index against the content of $\mathrm{CW}$ due to compaction and shearing is plotted in Fig. 12(a). The results indicate that for a given confining pressure, $\mathrm{BI}$ increases when the $\mathrm{CW}$ fraction increases. This was clearly due to the 
lower strength $\mathrm{CW}$ particles compared to the SFS particles. A bilinear relationship can be determined where the slope for blended specimens with $\mathrm{CW}>50 \%$ was higher than the remaining mixtures with a $\mathrm{CW}<50 \%$, and as expected, this slope increased with the increase in confining pressure. This implies that from a practical perspective, the greater volumetric strain (or settlement) attributed to particle breakage may occur with mixtures with a high percentage of CW. In Fig. 12(b), BI is plotted against the confining pressure for all CW-SFS mixtures, and for all the mixtures it increased with the increase in confining pressure, but at a decreasing rate. In other words, it was expected that the BI for each CW-SFS mixture would reach a threshold value where any further increase in the confining pressure would not significantly influence the extent of particle degradation.

\section{Practical Implications}

This study shows that despite mixing two completely different materials, the shear strength properties of the blended mixtures can be ideally represented within a unique empirical framework. These empirical relationships facilitate the determination of the isotropic compression line (Eqs 1a and 1b) and the peak stress ratio (or the peak friction angle) for different $\mathrm{CW}$ percentages over a range of confining pressure (Eq 8). In a practical point of view, these properties can now be adopted for any given mix ratio likely to be used on site.

The test results also show that CW-SFS mixtures meet common performance based criteria for typical reclamation conditions, with peak friction angles easily exceeding $30^{\circ}$ (Davies et al., 2011). Nevertheless, the excessive deformation associated with particle breakage during shearing may render the mixture unsuitable in practice under some circumstances. In such situations, it is beneficial to consider a design 
concept from a ‘critical strain’ perspective (e.g. Sakurai et al., 1993). An axial strain required to mobilise $50 \%$ of the peak deviatoric stress can be considered to define the critical axial strain of these blended mixtures, and this value is approximately $0.5 \%$ based on the test results shown in Fig. 10(b). Such a critical strain value corresponds well to the maximum allowable settlement of about 50mm for typical Port conditions considering a 10m fill thickness (Lai et al., 2011).

Among the different blended mixtures considered in this study, only the mix CW100-SFS0 exhibited strains exceeding the critical axial strain of $0.5 \%$ (Fig. $10(b))$, hence, it could be excluded from the choice of potential reclamation fills. In contrast, the CW75-SFS25 exhibited strains below a critical strain of $0.5 \%$ for a confining pressure less than $120 \mathrm{kPa}$ (i.e. corresponding to a maximum thickness of $8 \mathrm{~m}$ of a unit weight of $15 \mathrm{kN} / \mathrm{m}^{3}$ ). For the remaining mixtures, a fill thickness of 9$11 \mathrm{~m}$ could be placed on site.

\section{Conclusion}

Landfilling of industrial waste materials in Australia, particularly with coal wash and steel furnace slag has caused numerous environmental concerns in recent years due to their stockpiling in otherwise usable land. Utilization of these wastes as potential structural fill where they are approved by relevant environmental protection authorities in countries such as Australia would reap significant financial and environmental benefits. However, depending on the chemical composition, not all waste materials are approved as suitable landfills in an environmental and health view point. An experimental testing program was conducted on the blended CW and 
SFS under drained shearing, with the objective of evaluating its suitability as a port reclamation fill. The following conclusions were obtained from this study:

(1) It was observed through a series of isotropic compression tests that the specimen with a higher percentage of $\mathrm{CW}$ showed greater compressibility. This is because the CW particles were softer and more crushable compared to SFS particles which also demonstrated through the breakage analysis. In addition, the maximum past yield stress $\left(p^{*}\right)$ increased as the content of SFS was increased. A bilinear empirical equation of $v / v_{0}$ and $p^{\prime} / p^{*}$ was proposed to predict the isotropic compression of all the CW-SFS mixtures compacted under the same level of compaction energy.

(2) The stress-strain behaviour of CW-SFS mixtures was influenced by the percentage of CW. As the proportion of SFS in mixture increased, the peak deviatoric stress increased and the axial strain corresponding to the $q_{\text {peak }}$ decreased. The effect that the content of SFS had on the shear behaviour diminished at higher confining pressures exceeding $120 \mathrm{kPa}$.

(3) The volumetric strain at the end of the test was influenced quite significantly by the amount of $\mathrm{CW}$ in the mixture such that there was more contraction in those specimens with a higher percentage of $\mathrm{CW}$. Part of this volumetric contraction could be related to the degradation of coal wash particles (e.g. the BI values under $120 \mathrm{kPa}$ confining pressure for CW100-SFS0 and CW0SFS100 were $35 \%$ and $4.8 \%$, respectively).

(4) The shear strength envelopes of CW-SFS mixtures were found to be nonlinear and exhibited negligible cohesion, while the curvature decreased as the 
percentage of CW increased. The mixture with more SFS percentage showed higher shear strength than those with a higher CW percentage.

(5) It was observed that the addition of a small amount of SFS (approximately $25 \%$ ) increased the secant shear modulus significantly. The axial and shear strains corresponding to any levels of mobilized shear stress increased once the percentage of $\mathrm{CW}$ increased in the mixture. This implies that under same loading condition, larger deformation is associated with the mixtures having more CW content. However, based on the critical strain criterion proposed, only the mixture having $100 \%$ coal wash exhibits axial deformation over the prescribed allowance.

(6) The study on the breakage characteristics of CW-SFS mixtures during shearing revealed that under a given confining pressure, those specimens with less CW showed less particle breakage due to the influence of SFS. The rate of particle breakage for specimens with more than $50 \% \mathrm{CW}$ increased significantly. This change was markedly greater at confining pressures exceeding $60 \mathrm{kPa}$.

\section{Acknowledgments}

This study was funded by the Australian Research Council under an industry linkage project. The authors acknowledge the industrial partners Port Kembla Port Corporation (PKPC), Coffey Geotechnics, Douglas Partners, Menard Bachy, BHP Billiton-Illawarra Coal and Australian Steel Mill Services. Laboratory assistance provided by Mr Alan Grant is gratefully acknowledged. 


\section{References}

ASTM D1140-14, 2014: Standard Test Method for Amount of Material in Soils Finer Than No. $200 \quad(75-\mu \mathrm{m})$ Sieve, ASTM International, West Conshohocken, PA, www.astm.org.

ASTM D7181-11, 2011: Standard Test Method for Consolidated Drained Triaxial Compression Test for Soils, ASTM International, West Conshohocken, PA, www.astm.org.

Been, K. and Jefferies, M. G., 1985, "A State Parameter for Sands," Géotechnique, Vol. 35, No. 2, pp. 99-112.

Casagrande, A., 1936, "The Determination of the Pre-Consolidation Load and its Practical Signifcance," Proceeding of the first international conference on soil mechanics and foundation engineering, Cambridge, MA, June 22-26, Harvard Press, Cambridge, MA, pp. 60-64.

Cerato, A. and Lutenegger, A., 2006, "Specimen Size and Scale Effects of Direct Shear Box Tests of Sands," ASTM Geotech. Test. J., Vol. 29, No. 6, pp. 1-10.

Chiaro, G., Indraratna, B. and Tasalloti, S. M. A., 2014a, "Predicting the Behaviour of Coal Wash and Steel Slag Mixtures under Triaxial Conditions," Can. Geotech. J. Vol. 52, No. 3, pp. 367-373.

Chiaro, G., Indraratna, B., Tasalloti, S. M. A. and Rujikiatkamjorn, C., 2014b, "Optimisation of Coal Wash-Slag Blend as a Structural Fill," Proc. ICE Ground Improve., Vol. 168, No. 1, pp. 149-167.

Davies, P., Philip, R. E. D. and James, D. M., 2011, "Geotechnical Design for the Port Botany Expansion Project, Sydney," Proc. Inst. Civ. Eng. Geotech. Eng., Vol. 164, No. 3, pp.149-167.

Dippenaar, R., 2005, "Industrial Uses of Slag-the Use and Re-Use of Iron and Steelmaking Slags," Ironmaking Steelmaking, Vol. 32, No. 1, pp. 35-46.

Geiseler, J., 1996, "Use of Steelworks Slag in Europe," Waste Manage., Vol. 16, Nos. 1-3, pp. 59-63.

Hardin, B. O., 1985, "Crushing of Soil Particles," ASCE J. Geotech. Eng., ASCE, Vol. 111, No. 10, pp. 1177-1192.

Indraratna, B., Gasson, I. and Chowdhury, R. N., 1994, "Utilization of Compacted Coal Tailings as a Structural Fill," Can. Geotech. J., Vol. 31, No. 5, pp. 614623.

Indraratna, B., Ionescu, D. and Christie, H. D., 1998, "Shear Behavior of Railway Ballast Based on Large-Scale Triaxial Tests," J. Geotech. Geoenviron. Eng., Vol. 124, No. 5, pp. 439-449.

Indraratna, B., Lackenby, J. and Christie, D., 2005, "Effect of Confining Pressure on the Degradation of Ballast under Cyclic Loading," Géotechnique, Vol. 55, No. 4, pp. 325-328.

Indraratna, B., Rujikiatkamjorn, C. and Chiaro, G. 2013a, "Compaction of Coal Wash as Reclamation Fill." Proceedings of the 18th Southeast Asian Geotechnical Conference (18SEAGC) cum Inaugural AGSSEA Conference (1AGSSEA). Singapore, May 29-31, Research Publishing, Singapore, pp. 165-170.

Indraratna, B., Tennakoon, N., Nimbalkar, S. and Rujikiatkamjorn, C., 2013b, "Behaviour of Clay-Fouled Ballast under Drained Triaxial Testing," Géotechnique, Vol. 63, No. 5, pp. 410-419. 
La Rochelle, P., Leroueil, S., Trak, B., Blais-Leroux, L. and Tavenas, F., 1988, "Observational Approach to Membrane and Area Corrections in Triaxial Tests," Advanced Triaxial Testing of Soil and Rock, ASTM, STP 977, R. T. Donghe, R. C. Chaney, and M. L. Silver, Eds., ASTM International, West Conshohocken, PA, pp. 715-731.

Lai, Z., His, J., Rheinberger, T. and Andrews, T., 2011, "Geotechnical Offshore Site Investigation and Reclamation Design at Port Kembla," Proceedings of Australian Geomechanics Society Sydney Symposium, Coastal and Marine Geotechnics: Foundations and Trade. Sydney, Australia. pp. 61-72.

Leventhal, A., 1996, "Coal Washery Reject as an Engineered Material," National Symposium on the Use of Recycled Materials in Engineering Construction. Sydney, NSW, Australia, May 30-31, ARRB Group Ltd, Vermont South, Victoria, Australia, pp.54-59.

Lim, T.-T. and Chu, J., 2006, "Assessment of the Use of Spent Copper Slag for Land Reclamation," Waste Manage. \& Res., Vol. 24, No. 1, pp. 67-73.

Malasavage, N., Jagupilla, S., Grubb, D., Wazne, M. and Coon, W., 2012, "Geotechnical Performance of Dredged Material-Steel Slag Fines Blends: Laboratory and Field Evaluation," J. Geotech. Geoenviron. Eng., Vol 138, No. 8, pp. 981-991.

Massarsch, K. R., 1991, "Deep Soil Compaction Using Vibratory Probes," Deep Foundation Improvements: Design, Construction, and Testing, ASTM STP 1089, M. I. Esrig and R. C. Bachus, Eds., ASTM International, West Conshohocken, PA, pp. 297-319.

Modoni, G. and Gazzellone, A., 2011, "Experimental Observations on the Critical State of Granular Materials," Deformation Characteristics of Geomaterials, IOS Press, Clifton, VA, pp. 850-857.

Ni, Q., Powrie, W., Zhang, X. and Harkness, R., 2000, "Effect of Particle Properties on Soil Behavior: 3-D Numerical Modeling of Shearbox Tests," Numerical Methods in Geotechnical Engineering. G. M. Filz and D. V. Griffiths, Eds., ASCE, Reston, VA, pp. 58-70.

Okabue, C. O. and Ochulor, O. H., 2007, "The Potential of Cemented-Stabilized Coal-Reject as Construction Material," Bull. Eng. Geol. and the Environ., Vol. 66, No. 2, pp. 143-151.

Pusadkar, S. S. and Ramasamy, G., 2005, "Collapse Behavior of Compacted Coal Ash Fills," Geotech. Test. J., Vol. 28, No. 3, pp. 297-304.

Rai, A., Prabakar, J., Raju, C. B. and Morchalle, R. K., 2002, "Metallurgical Slag as a Component in Blended Cement," Constr. Build. Mate., Vol. 16, No. 8, pp. 489-494.

Roscoe, K. H., Schofield, A. N. and Thurairajah, A., 1963, "Yielding of Clays in States Wetter than Critical," Géotechnique, Vol. 13, No. 3, pp. 211-240.

Rowe, P. W., 1962, "The Stress-Dilatancy Relation for Static Equilibrium of an Assembly of Particles in Contact," Proc. R. Soc. Lond. Ser. A, Vol. 269, No. 1339, pp. 500-527.

Rujikiatkamjorn, C., Indraratna, B. and Chiaro, G. 2013, "Compaction of Coal Wash to Optimise its Utilisation as Water-Front Reclamation Fill," Geomech. Geoeng., Vol. 8, No. 1, pp. 36-45.

Safiuddin, M., Jumaat, M. Z., Salam, M. A., Islam, M. S. and Hashim, R., 2010, "Utilization of Solid Wastes in Construction Materials," Int. J. Phys. Sci., Vol. 5, No. 13, pp. 1952-1963. 
Sakurai, S., Kawashima, I. and Otani, T., 1993, "A Criterion for Assessing the Stability of Tunnels," Proceedings of EUROCK'9, Lisbon, Portugal, Jun 2124, International Society for Rock Mechanics, Lisbon, Portugal, pp. 969-973.

Wang, G., 2010, "Determination of the Expansion Force of Coarse Steel Slag Aggregate," Constr. Build. Mater., Vol. 24, No. 10, pp. 1961-1966.

Wang, G., Wang, Y. and Gao, Z., 2010, "Use of Steel Slag as a Granular Material: Volume Expansion Prediction and Usability Criteria," J. Hazard. Mater., Vol. 184, Nos. 1-3, pp. 555-560.

Watts, K. S. and Cooper, A., 2011, "Compaction of Fills in Land Reclamation by Rapid Impact," Proc. Inst. Civ. Eng., Geotech. Eng., Vol. 164, No. 3, pp. 181-193.

Zekkos, D. and Flanagan, M., 2011, "Case Histories-based Evaluation of the Deep Dynamic Compaction Technique on Municipal Solid Waste Sites," GeoFrontiers 2011, Dallas, TX. Mar 13-16, J. Han and D. E. Alzamora, Eds., ASCE, Reston, VA, pp. 529-538. 
TABLE 1-Experimental testing program for triaxial testing and summary of parameters for the shear strength, the critical state line, and the isotropic compression line.

\begin{tabular}{|c|c|c|c|c|c|c|c|c|c|c|c|c|}
\hline \multirow{2}{*}{ Mixture } & \multicolumn{3}{|c|}{$\begin{array}{c}\text { Initial } \\
\text { conditions }\end{array}$} & \multicolumn{3}{|c|}{ Peak state } & \multicolumn{3}{|c|}{ CSL } & \multicolumn{3}{|c|}{ ICL } \\
\hline & $G_{s}$ & $\begin{array}{c}\sigma_{3}^{\prime} \\
(\mathrm{kPa})\end{array}$ & $v_{0}$ & $\begin{array}{l}p_{\text {peak }}^{\prime} \\
(\mathrm{kPa})\end{array}$ & $\begin{array}{l}q_{\text {peak }} \\
(\mathrm{kPa})\end{array}$ & $\begin{array}{l}\phi_{p}^{\prime} \\
\left({ }^{\circ}\right)\end{array}$ & $\Gamma$ & $\lambda_{\mathrm{CSL}}$ & M & $\mathrm{N}$ & $\lambda_{\text {ICL }}$ & $\kappa$ \\
\hline \multirow{4}{*}{ CW0-SFS100 } & \multirow{4}{*}{3.34} & 30 & 1.596 & 98 & 191 & 47.9 & \multirow{4}{*}{1.709} & \multirow{4}{*}{0.019} & \multirow{4}{*}{1.545} & \multirow{4}{*}{1.789} & \multirow{4}{*}{0.019} & \multirow{4}{*}{0.0027} \\
\hline & & 60 & 1.597 & 167 & 314 & 46 & & & & & & \\
\hline & & 120 & 1.587 & 293 & 510 & 42.7 & & & & & & \\
\hline & & 220 & 1.577 & 453 & 741 & 41.1 & & & & & & \\
\hline \multirow{4}{*}{ CW25-SFS75 } & \multirow{4}{*}{3.01} & 30 & 1.568 & 89 & 170 & 46.8 & \multirow{4}{*}{1.827} & \multirow{4}{*}{0.052} & \multirow{4}{*}{1.517} & \multirow{4}{*}{1.869} & \multirow{4}{*}{0.058} & \multirow{4}{*}{0.0031} \\
\hline & & 60 & 1.565 & 158 & 291 & 44.8 & & & & & & \\
\hline & & 120 & 1.560 & 250 & 393 & 38.6 & & & & & & \\
\hline & & 220 & 1.546 & 447 & 681 & 37.5 & & & & & & \\
\hline \multirow{4}{*}{ CW50-SFS50 } & \multirow{4}{*}{2.73} & 30 & 1.517 & 78 & 141 & 44.1 & \multirow{4}{*}{1.817} & \multirow{4}{*}{0.063} & \multirow{4}{*}{1.496} & \multirow{4}{*}{1.870} & \multirow{4}{*}{0.065} & \multirow{4}{*}{0.0034} \\
\hline & & 60 & 1.515 & 147 & 261 & 43.2 & & & & & & \\
\hline & & 120 & 1.504 & 242 & 367 & 37.4 & & & & & & \\
\hline & & 220 & 1.495 & 440 & 660 & 37 & & & & & & \\
\hline \multirow{4}{*}{ CW75-SFS25 } & \multirow{4}{*}{2.51} & 30 & 1.499 & 72 & 130 & 43.9 & \multirow{4}{*}{1.808} & & & & & \\
\hline & & 60 & 1.493 & 142 & 246 & 42.4 & & 0067 & 1.185 & 1864 & 0067 & 00045 \\
\hline & & 120 & 1.481 & 242 & 367 & 37.4 & & $0.06 /$ & 1.485 & 1.864 & $0.06 /$ & 0.0045 \\
\hline & & 220 & 1.470 & 436 & 650 & 36.8 & & & & & & \\
\hline & & 30 & 1.451 & 73 & 124 & 43.5 & & & & & & \\
\hline CW 100 SESO & 27 & 60 & 1.451 & 124 & 192 & 38.2 & 1685 & 0.056 & 1430 & 1737 & 0.056 & 00050 工 \\
\hline CWIOU-SFSO & 2.21 & 120 & 1.439 & 242 & 348 & 35.6 & 1.085 & 0.050 & 1.439 & 1.131 & 0.050 & 0.0000 \\
\hline & & 220 & 1.424 & 433 & 622 & 35.6 & & & & & & \\
\hline
\end{tabular}




\section{List of Figures}

FIG. 1-Original and adopted particle size distributions of coal wash and steel furnace slag

FIG. 2-Isotropic compression lines for all CW-SFS mixtures (the vertical axis was normalised to the initial specific volume of each mixture for a better comparison)

FIG. 3-Results of isotropic compression test for all CW-SFS mixtures in double normalisation space $\left(v / v_{0}-p^{\prime} / p^{*}\right)$

FIG. 4-Behaviour of CW50-SFS50 mixture under isotropically consolidated drained tests

FIG. 5-Behaviour of all CW-SFS mixtures under isotropically consolidated drained tests under confining pressures; (a) $30 \mathrm{kPa}$ and (b) $120 \mathrm{kPa}$

FIG. 6- Stress paths and the location of CSLs in $v$ - $\ln p^{\prime}$ space

FIG. 7-Variation of volumetric strain at critical state over confining pressure for all CW-SFS mixtures under four confining pressures

FIG. 8- Shear strength characteristics of CW-SFS mixtures: (a) effect of confining pressure on the peak deviatoric stress with non-linear shear envelopes, (b) variation of peak friction angle and peak stress ratio against confining pressure for CW-SFS mixtures under drained triaxial condition

FIG. 9-Variation of secant shear modulus $\left(G_{s e c}\right)$ with shear strain under different confining pressures for CW-SFS mixtures

FIG. 10 - Effect of confining pressure and the percentage of coal wash on the (a) the axial strain corresponding to peak deviatoric stress and (b) the axial strain at $0.5 q_{\text {peak }}$ FIG. 11-Definition of CW-SFS mixtures breakage index modified after Indraratna et al., 2005 
FIG. 12-Breakage analysis on CW-SFS mixtures (a) the effect of the percentage of coal wash on BI under four confining pressures and (b) the effect of confining pressure on the BI for each CW-SFS mixtures 


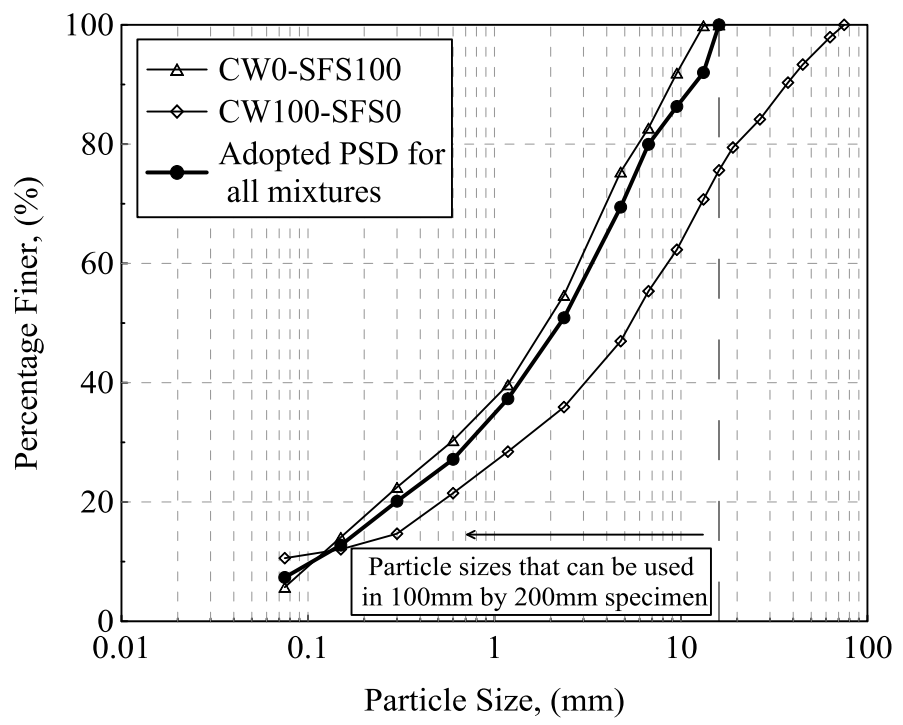

FIG. 1-Original and adopted particle size distributions of coal wash and steel furnace slag 


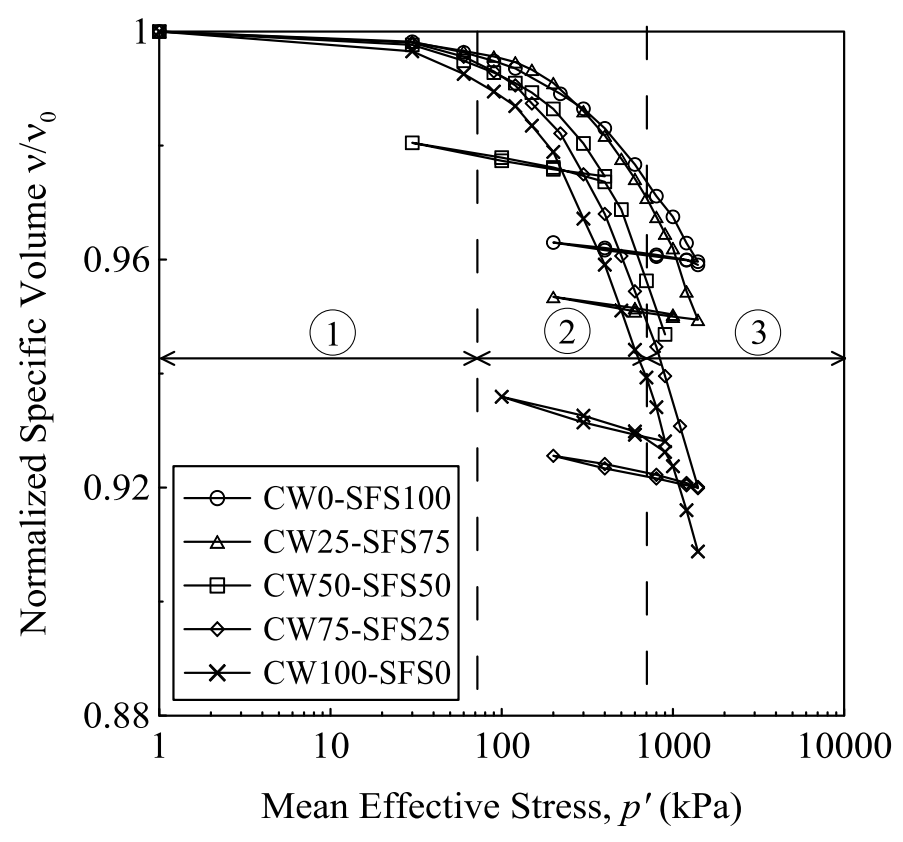

FIG. 2-Isotropic compression lines for all CW-SFS mixtures (the vertical axis was normalised to the initial specific volume of each mixture for a better comparison) 


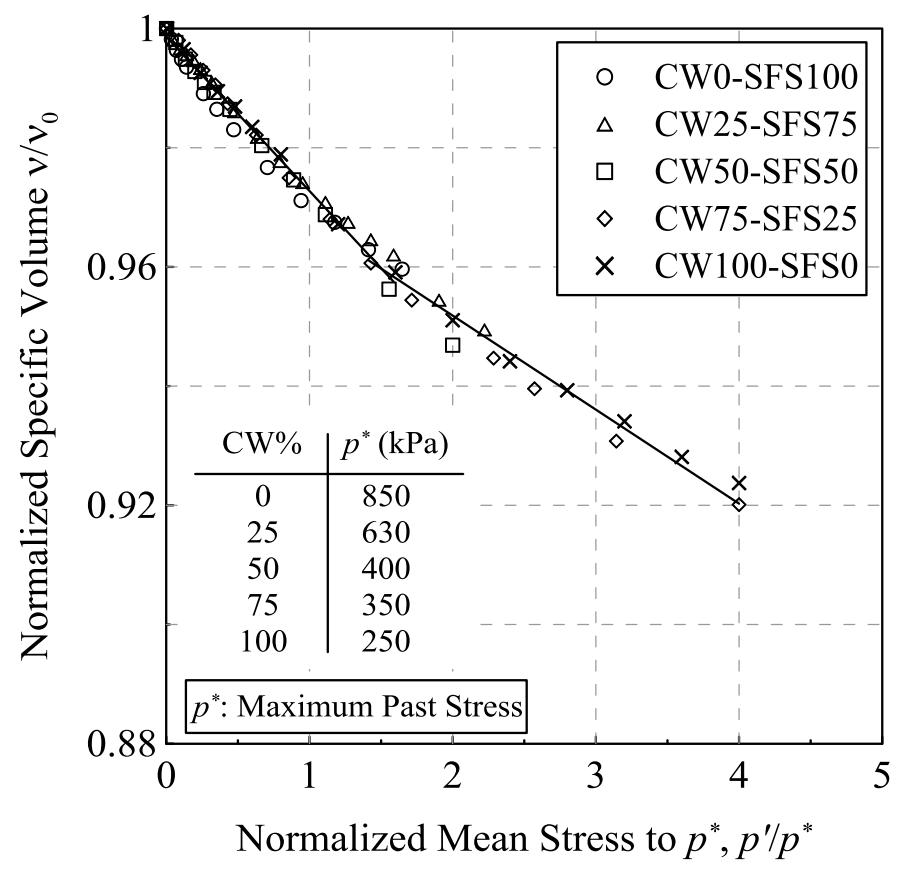

FIG. 3-Results of isotropic compression test for all CW-SFS mixtures in double normalisation space $\left(v / v_{0}-p^{\prime} / p^{*}\right)$ 


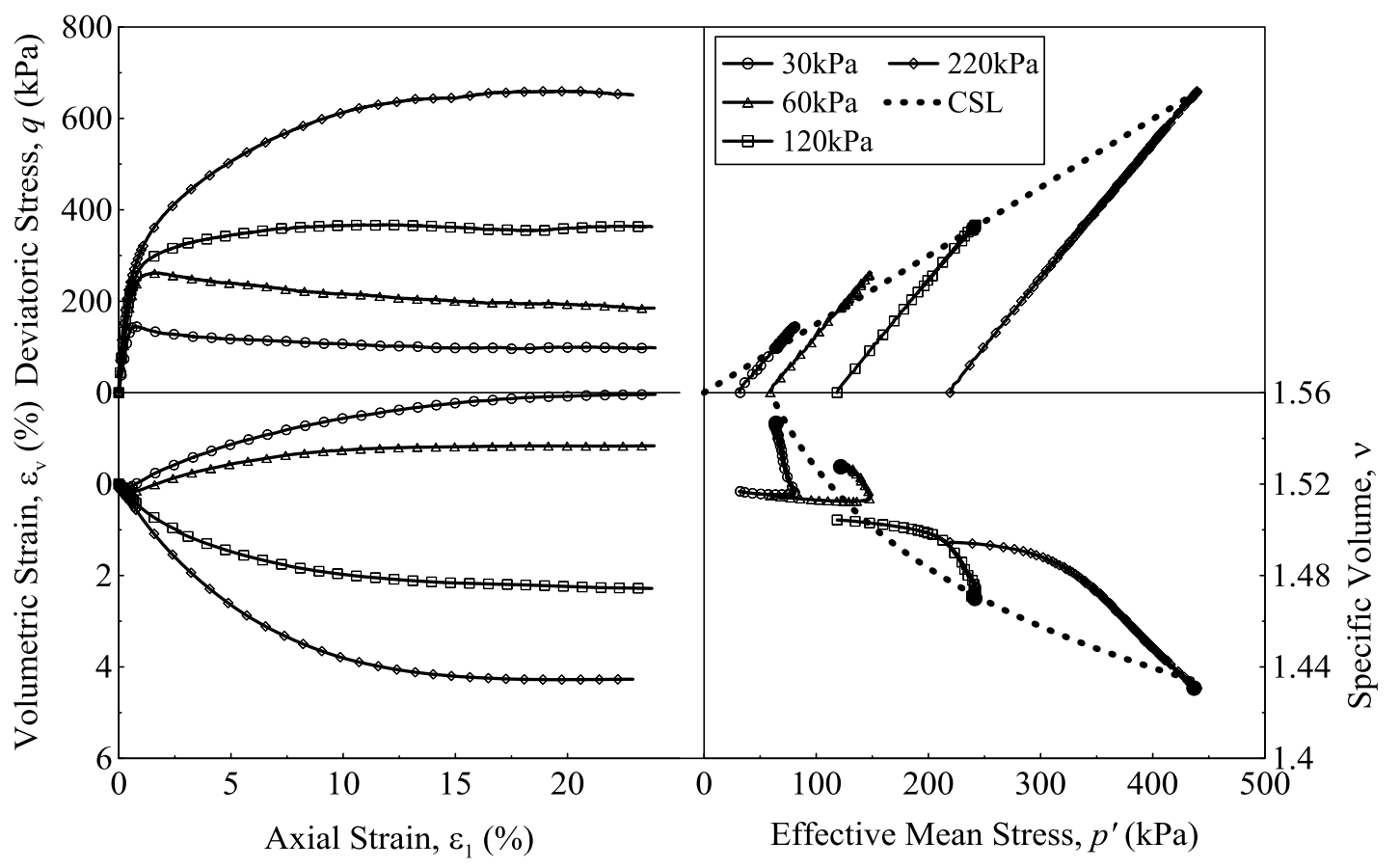

FIG. 4-Behaviour of CW50-SFS50 mixture under isotropically consolidated drained tests 

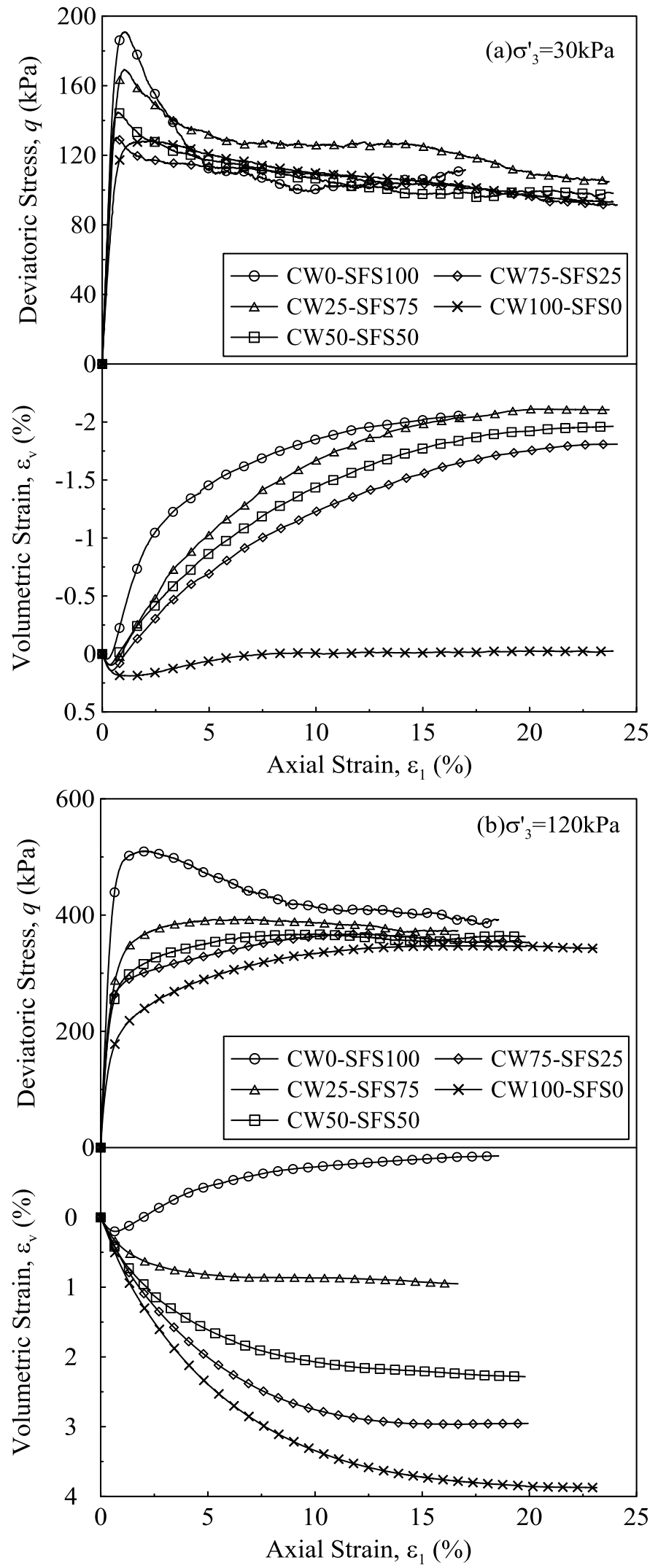

FIG. 5-Behaviour of all CW-SFS mixtures under isotropically consolidated drained tests under confining pressures; (a) $30 \mathrm{kPa}$ and (b) $120 \mathrm{kPa}$ 


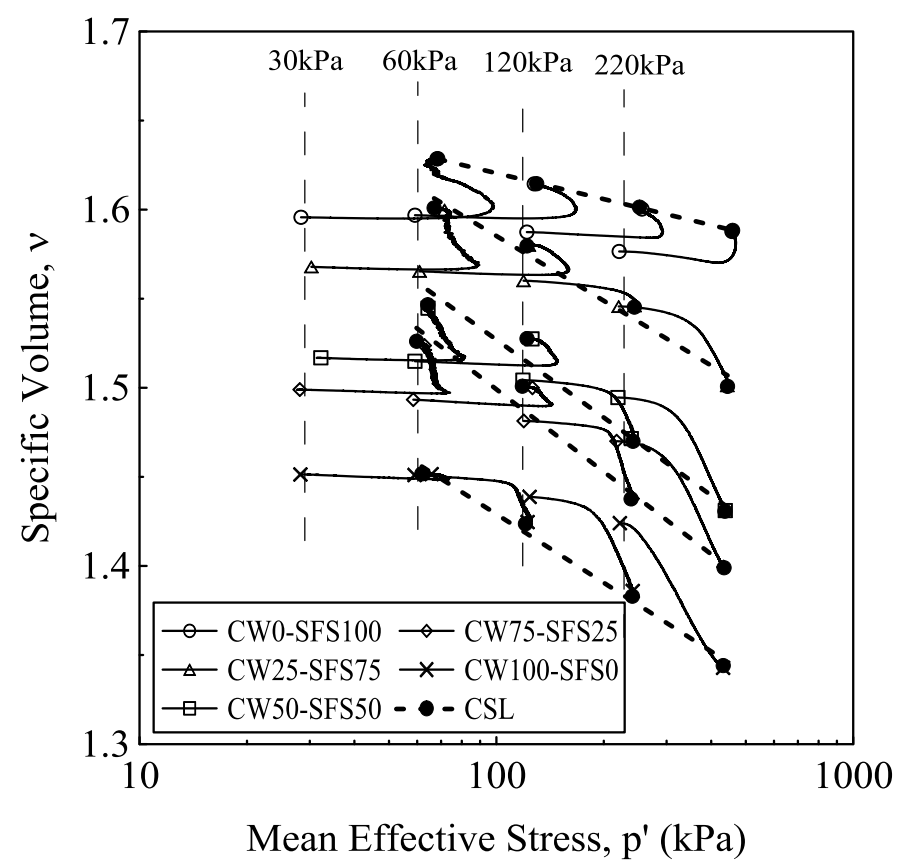

FIG. 6-Stress paths and the location of CSLs in v-lnp' space 


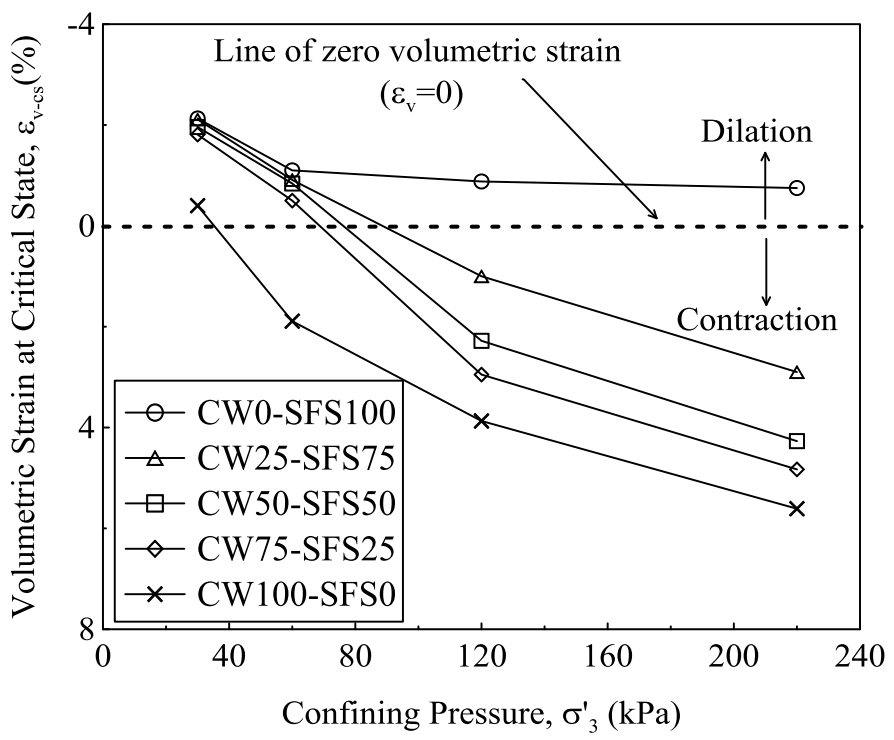

FIG. 7-Variation of volumetric strain at critical state over confining pressure for all CW-SFS mixtures under four confining pressures 

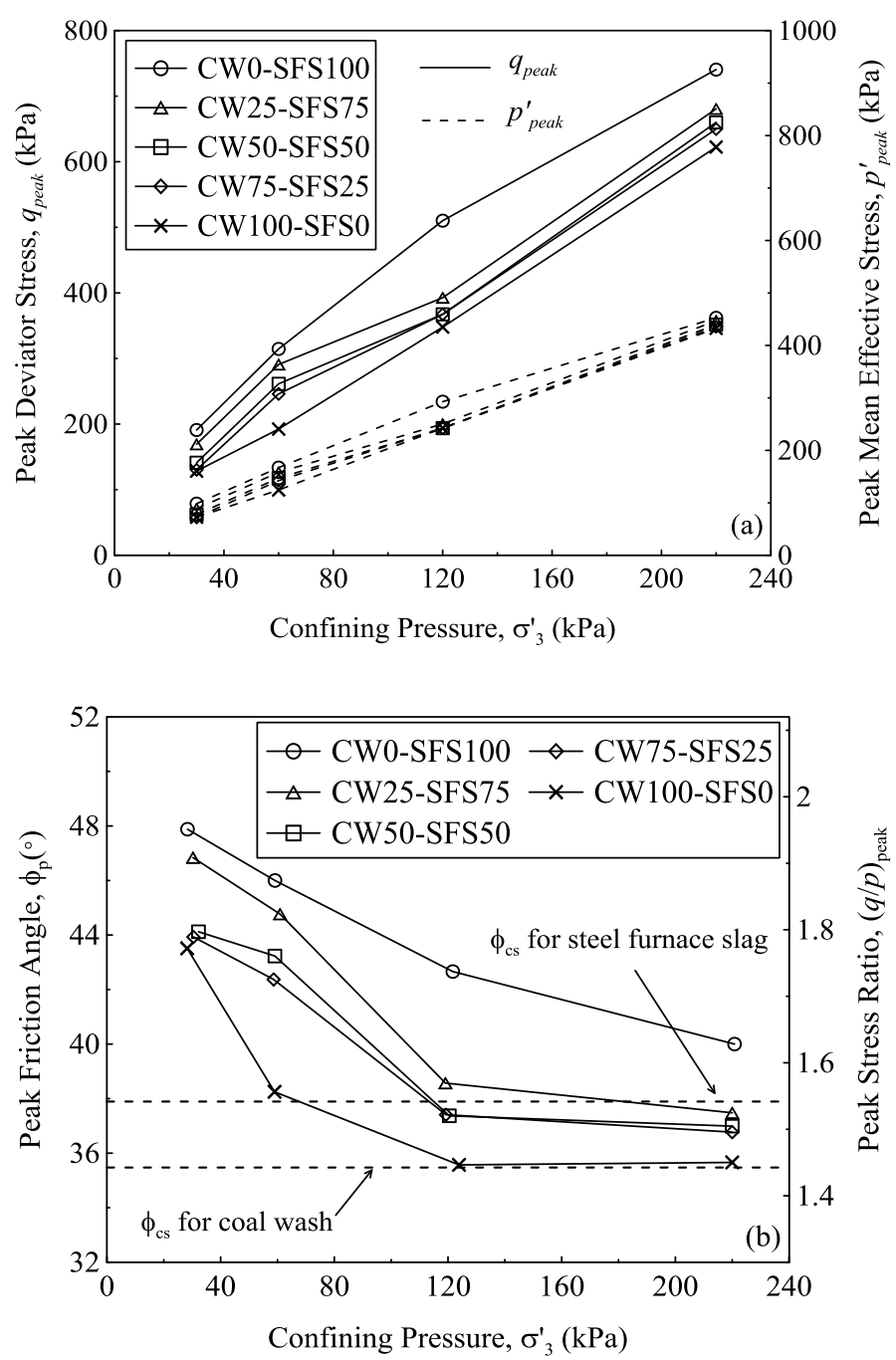

FIG. 8-Shear strength characteristics of CW-SFS mixtures: (a) effect of confining pressure on the peak deviatoric stress with non-linear shear envelopes, (b) variation of peak friction angle and peak stress ratio against confining pressure for CW-SFS mixtures under drained triaxial condition 

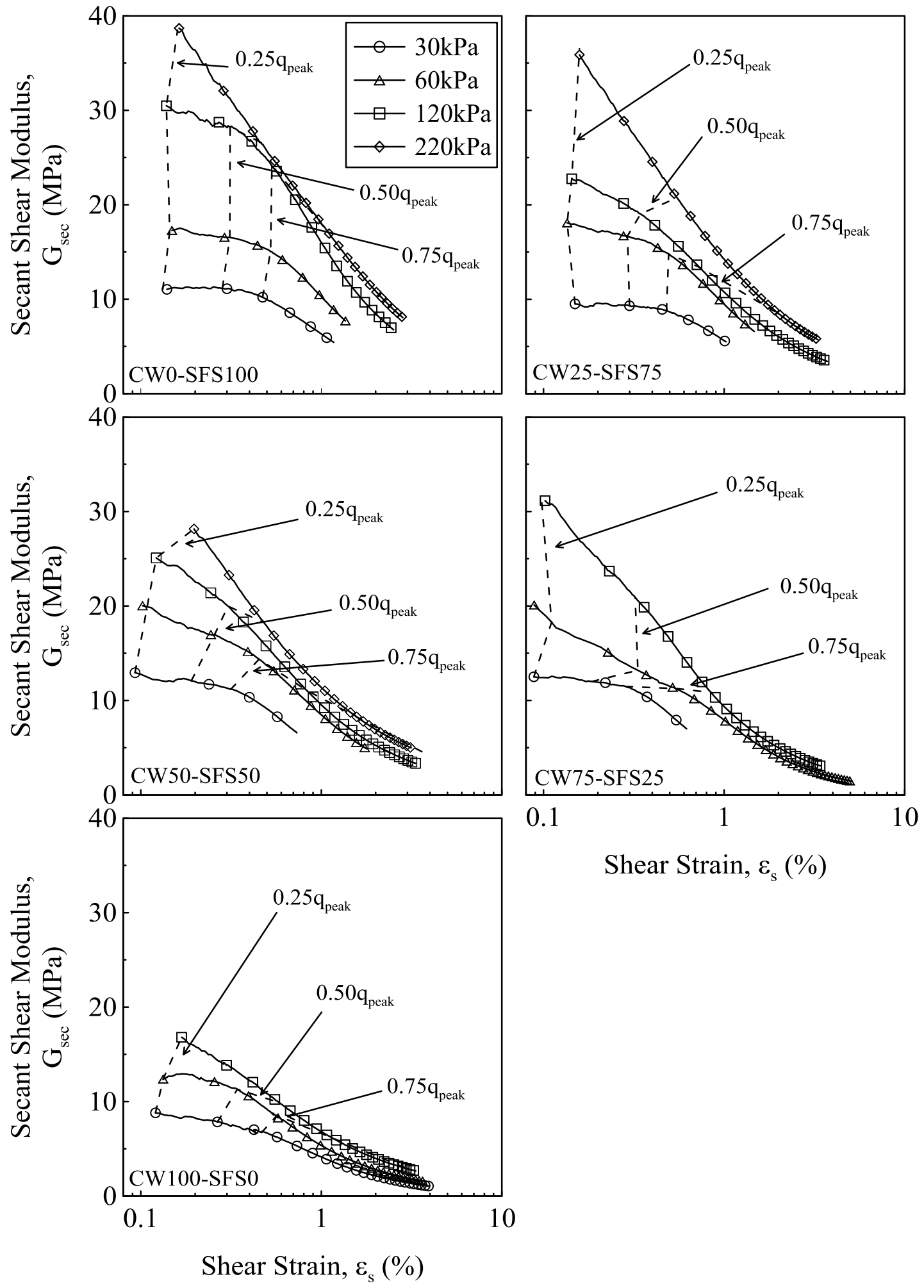

Shear Strain, $\varepsilon_{\mathrm{s}}(\%)$

FIG. 9-Variation of secant shear modulus $\left(G_{s e c}\right)$ with shear strain under different confining pressures for $C W$-SFS mixtures 


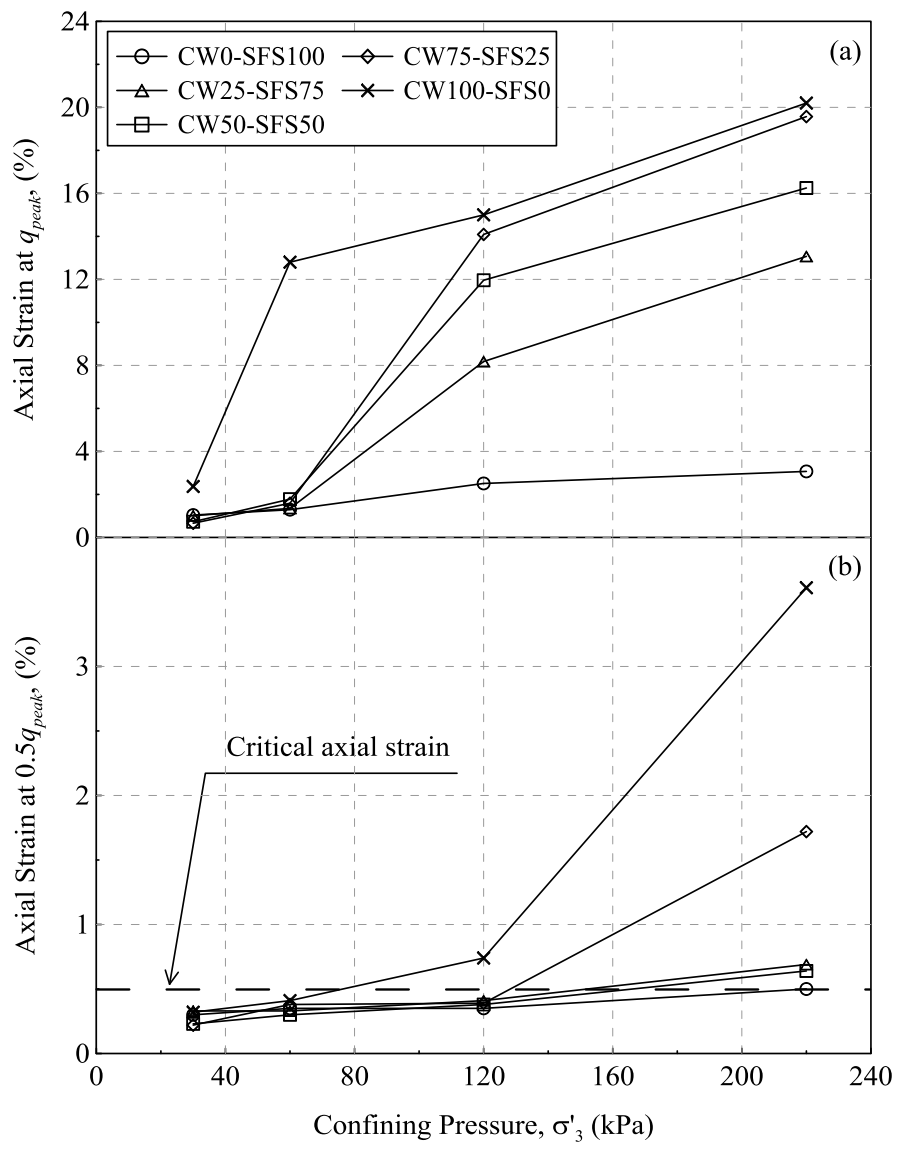

FIG. 10-Effect of confining pressure and the percentage of coal wash on the (a) the axial strain corresponding to peak deviatoric stress and $(b)$ the axial strain at $0.5 q_{\text {peak }}$ 


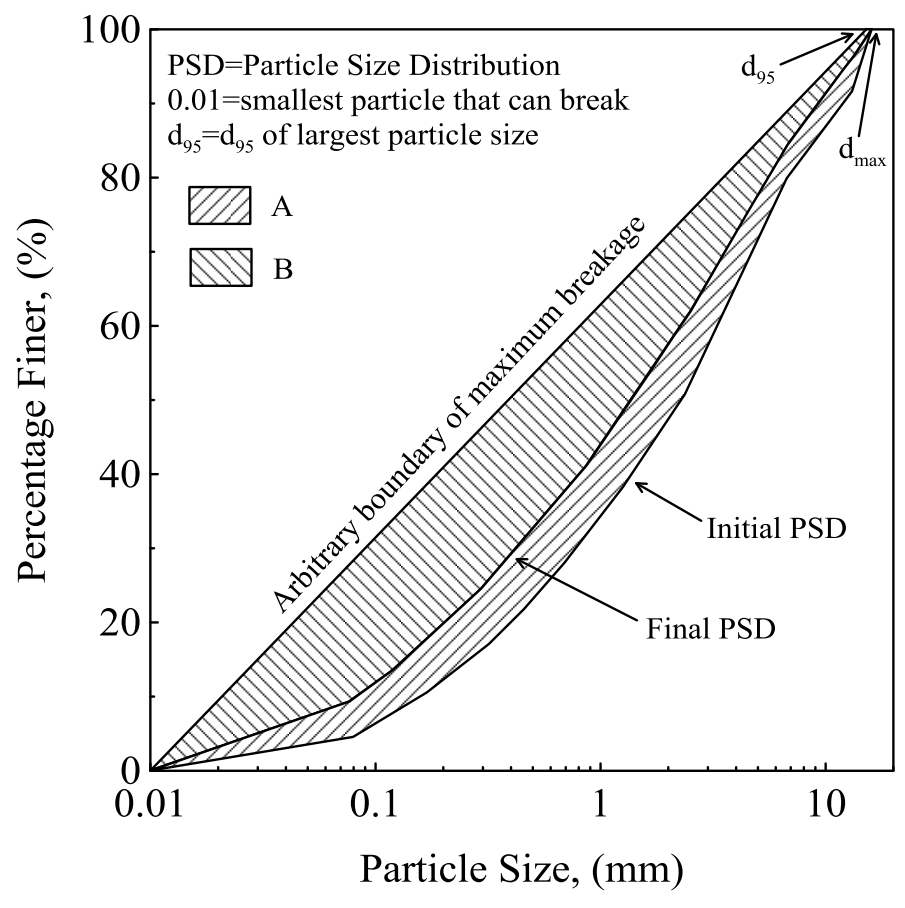

FIG. 11-Definition of CW-SFS mixtures breakage index modified after Indraratna et al., 2005 

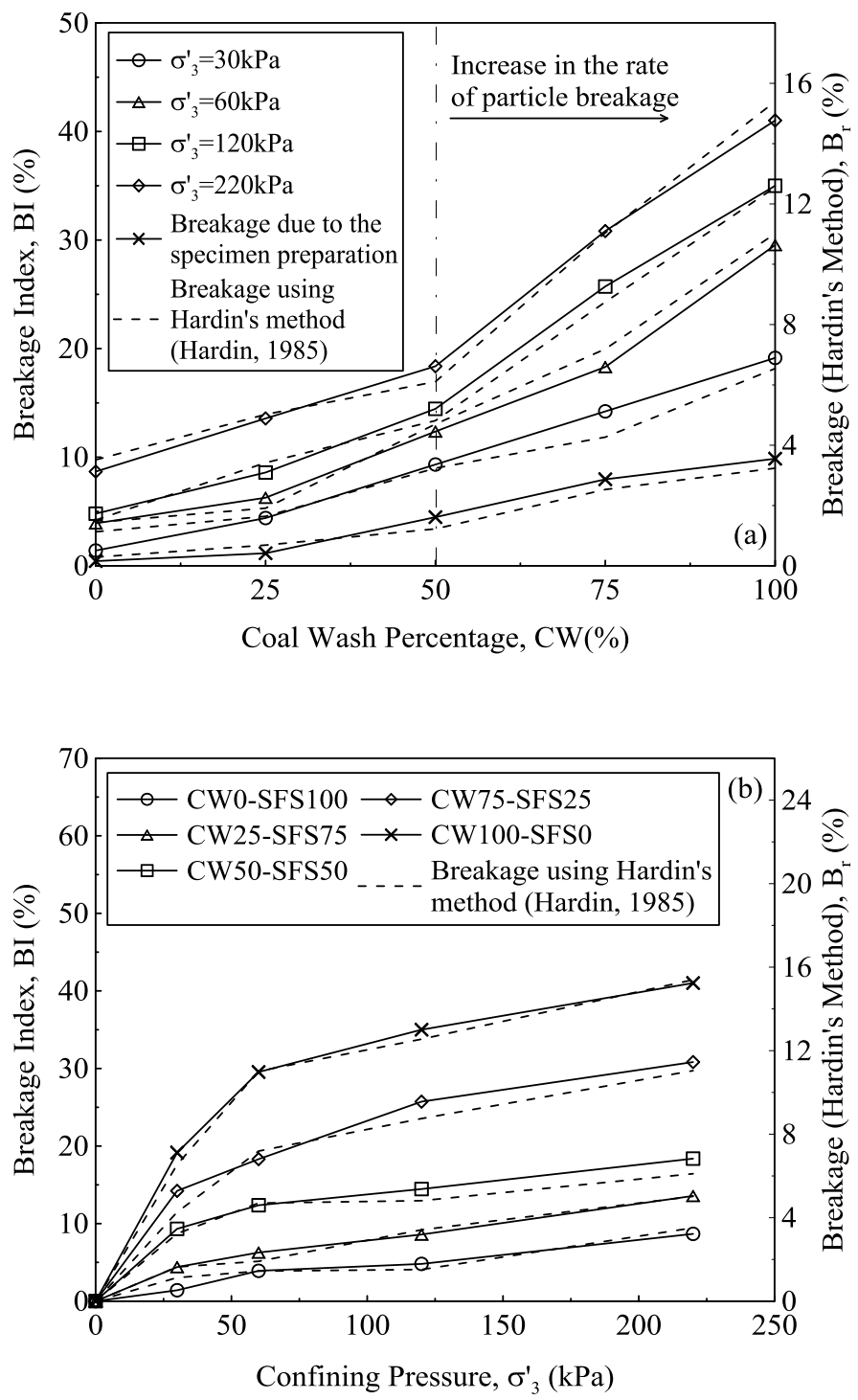

FIG. 12-Breakage analysis on CW-SFS mixtures (a) the effect of the percentage of coal wash on BI under four confining pressures and (b) the effect of confining pressure on the BI for each CW-SFS mixtures 